increase the capacity to support more patients within existing resources and deliver a wider range of therapeutic interventions.

To achieve accessibility for the maximum number of patients, services were established in eight different locations including providing therapy within GP practices and community halls, and also inreaching to meet the needs of dementia patients in a nursing home setting.

Whilst the philosophy was unchanged, the service was redesigned and continues to develop responsively and with flexibility. A diverse range of therapeutic interventions are available and a plan of care is tailored to meet the individual patient and carer needs following assessment. New volunteer roles with specific profiles were developed to augment the nursing staff. The community engagement officer increases awareness to diverse and often hard to reach groups.

Evidence from patient reported outcome measures, piloting and evaluation enable creative and on going service design to meet emerging needs. Structured training programmes for staff and volunteers continue.

Increased access to the service is evidenced by data collection, demonstrating a $51 \%$ increase countywide, with $70 \%$ increase of 18-64 age group and 74\% increase in non cancer patients, demonstrating greater opportunities for those with life limiting illnesses to be supported to reach their full potential.

This service will be sustained and enhanced by working in partnership, signposting, and through additional innovation such as commissioned Carers Assessment.

- Lincolnshire Research Observatory.

http://www.research-lincs.org.uk/Latest-Population.aspx

\section{P24 TESSERA AND BEYOND}

1,2Jannette Smith, 'Julia O'Neill. 'Hospice Care for Burnley and Pendle, Burnley, Lancashire, ${ }^{2}$ East Lancashire Hospitals NHS Trust

\subsection{6/bmjspcare-2013-000591.46}

For the past 10 years, Pendleside have made one of their Day Therapy days available to non palliative patients. The day referred to as Early Diagnosis Day (EDD) was essentially aimed at patients with a recent cancer diagnosis being treated with curative intent.

Whilst the EDD was innovative and popular initially, more lately it had become stagnated and predicable. It was also recognised that it was not fully in line with the work being done locally and nationally which has "survivorship" as a key element.

Patients were consulted and responded enthusiastically to the ideas suggested for service improvement. Indeed the TESSERA name was chosen by a patient group.

It is acknowledged that a cancer diagnosis can be shattering and life changing. With appropriate support patients can and do rebuild their lives. It was on this basis that the name was chosen. A Tessera is an individual tile used in creating a mosaic. Which was thought to be an ideal representation of rebuilding in the finest form.

TESSERA:

Together,

Experience,

Solace,

Survivorship,

Empowerment,

Rehabilitation,

Adapt.
TESSERA offers an eight week rolling programme of activities, presentations and interactive workshops delivered by outside agencies in addition to Hospice and Trust staff. This is further complemented by peer and healthcare support including an extended MDT.

The day runs from $10 \mathrm{am}-3 \mathrm{pm}$.

Sessions are offered using a menu 'pick and mix' system. Attendance can be one session or a full day (and anything in between). Graduated arrival enables higher patient flow.

Exercise classes, Tai Chi, Emotional Wellbeing and Fatigue Management groups are timetabled as fixed sessions. These all contribute to the ultimate aim of empowering patients to regain a lifestyle that is enriched both emotionally and physically.

\section{P25 TRANSFORMING DAY CARE SERVICES ACROSS BOUNDARIES}

Gaberielle Linehan, Caroline Snow. St Raphael's Hospice

\subsection{6/bmjspcare-2013-000591.47}

South of England Hospice, population of 370,000-380.000, 14 inpatient beds and community team supporting approximately 300 patients.

Day care services previously delivered via a care model unchanged in twenty years; all day attendance with no defined focus.

A service review in 2011 demonstrated that on average 33 patients attended over four days from a community case load of approximately 300 (cost $£ 4545.45$ per patient). Referrals from the CNS team took on average two to three weeks to be processed to arrange a 'look around'. Following this $40 \%$ of patients were unable to attend due to condition deterioration. A CNS caseload review demonstrated the patient demographic was changing to younger more discerning patients wanting specific treatments for attendance.

Day care services were suspended in May 2012 for a refurbishment project. This allowed a rethink on the parameters of the service, aiming to focus, energise and engage.

Service reopened in October 2012 delivering morning or afternoon sessions each with a specific focus. Lead for day care changed to a therapist with nurse support. Activities include, Hope course, art and craft, yoga, music therapy, bathing service on one afternoon, complimentary therapies, lunch clubs and an information centre once a month for all patients /relatives.

Focus of engagement changed from CNS referral to direct patient contact with a choice in activities. Attendance: STEP 1three months accessing two sessions weekly plus a lunch club: then STEP 2- choice of one activity monthly and a lunch club. Eliminates need for discharge and allows for ongoing monitoring and engagement with hospice.

In the six months to March 2013 there has been engagement with 89 patients', representing an increase of $166.8 \%$ over the 6 month period reducing the cost per patient to $£ 1685.39$.

User feedback is positive and active ongoing service review and development is planned.

\section{Community engagement and volunteering}

\section{\begin{tabular}{|l|l}
\hline P26 ESV IS JUST THE START \\
\hline
\end{tabular}}

Karen Filsell, Gillian Levy. Children's Hospice Association Scotland, Edinburgh, UK

10.1136/bmjspcare-2013-000591.48 
Introduction The organisation has been involved for some time with Employer Supported Volunteering. In recent years we have seen a significant increase in the number of requests for Employer Supported Volunteering projects. At the same time, the fundraising team was tasked with further developing corporate relationships.

Aims The aims were to:

- develop a more professional response,

- develop creative and interesting opportunities

- use ESV as a springboard for further engagement with companies.

Methods The Voluntary Services and Corporate Relationships teams developed an approach which included clear policy and procedures and a project bank across the organisation. All enquires are channelled through the Corporate Relationships team, and visits to companies are made before and after each activity to manage expectations and develop the relationship further.

Activities in the hospices include gardening, wrapping Christmas presents, and putting up or taking down Christmas decorations. Whilst in retail ESV volunteers became involved in window dressing challenges, as secret shoppers, or taking part in sorting challenges which are also involve the collection of donated goods from the participating company.

The Fundraising team also seek support from companies with bucket shakes, bag packs, and marshalling at large events.

Outcomes Outcomes from the project include:

- Completion of much needed organisational projects, eg development of play areas, sorting of stock for retail

- Stronger, more productive partnerships with companies

- Long term relationships - companies want to come back

- Individuals becoming regular volunteers

Conclusion The organisation is committed to further investment in this work and acknowledges that developing these relationships takes time and energy. The organisation has benefited greatly from creative and engaging projects that have provided benefit to children, young people and families and have helped develop strong corporate partnerships through volunteering.

\section{P27 VOLUNTEER HOSTS}

Karen Clarke. St Wilfrid's Hospice, Eastbourne, Eastbourne, UK

\subsection{6/bmjspcare-2013-000591.49}

Background Autumn 2013 the hospice relocates to its new 20bedded facility. To offer a more worthwhile and less segregated volunteering experience, a generic volunteer role was created to replace Ward Helpers, Receptionists and Day Therapy Helpers. Aim

- Offer a positive, friendly greeting to visitors via a wellinformed, approachable "Host"

- Create a volunteer 'workforce' aligned to the vision of the hospice as a community resource

- Develop a flexible team able to respond to changing demands

- Provide peer support and integration.

Approach
- Consultation meetings: (i) volunteers affected and (ii) wider volunteer community. Meeting 1: Design and vision for the new building; Meeting 2: Potential role changes and consultation; Meeting 3: New roles and invitation to express interest.

- Consultation with a volunteer focus group resulting in:

$$
\begin{aligned}
& \text { creation of volunteer Host Liaison role (to over- } \\
& \text { see the volunteer Hosts on duty) } \\
& \text { - weekly rotation of Hosts } \\
& \text { - Host 'uniform'. }
\end{aligned}
$$

- Visits to the new hospice.

\section{Outcomes}

- 77 existing volunteers have applied and been offered Host roles

- 49 unsolicited external applications received.

- Feedback:

- "I now feel very excited and privileged to be part of the beginning of the new life of the Hospice."

- the "meeting did a good job of clarifying what's proposed and is another step towards the new set-up.... All feeling very positive"

- "... having walked around the new build today, and with your input as to how life will probably be I cannot think of anything better to offer our town and neighbourhood".

Application "Volunteers: Vital to the future of Hospice Care" (2012), states that volunteers are vital to the high quality experience of those who seek help from hospices. The role of volunteer Hosts demonstrates a new approach to volunteering and offers volunteers a rewarding and life enhancing experience.

\section{P28 ENGAGING VOLUNTEERS IN DATA COLLECTION TO EVIDENCE SERVICE ACCOUNTABILITY}

Linda Henson. St. Catherine's Hospice, Crawley, UK

\subsection{6/bmjspcare-2013-000591.50}

Hospices are required to measure performance as evidence in making a difference to the lives of the communities they serve and to use this data to improve service delivery. This demands workforce capacity and capability as well as sustainability in data collection processes. In an innovative approach, a hospice successfully widened the scope for volunteers within their organisation, by engaging them in data collection using the St Christopher's Hospice Patient Priorities Measure (SKIPP), a validated outcome measure for use in specialist palliative care settings. SKIPP was piloted for 3 months across the day and inpatient unit. A project lead trained and managed volunteers in the agreed pilot process. Key clinical champions were identified in each department to support the volunteers administering the questionnaires and to discuss any emerging 'surprise' concerns requiring a more immediate clinical response. Supervision/support meetings were agreed monthly for volunteers, facilitated by the project lead. The volunteers were very committed, evidenced by the $82 \%$ rate of returned initial questionnaires. All trained volunteers remained with the programme and reported feeling very positive, valued and recognized for the life skills and experience they brought and for being able to contribute to hospice service evaluation. The pilot proved very successful as volunteer engagement limited the opportunity for bias through nurse 'gatekeeping' and reduced the need for the nursing capacity to undertake this additional work. The volunteer's feedback contributed 